\title{
Exposure to toluene in the printing industry is associated with subfecundity in women but not in
} men

\author{
Anita Plenge-Bönig, Wilfried Karmaus
}

\begin{abstract}
Objective-To examine the possible influence of exposure to toluene on human fertility.

Methods-In a cross sectional study, a sample of 150 male and 90 female printing industry workers were interviewed retrospectively on reproductive experience with a modified version of the European study of infertility and subfecundity questionnaire. Exposure categories comprised job descriptions and information on exposure measurements obtained by industrial hygienists. The fecundability ratio (FR) was estimated on the basis of time to pregnancy (TTP) or periods of unprotected intercourse not leading to pregnancy (PUNP) by means of survival analysis with proportional hazard models. Confounders such as age, ethnicity, smoking, parity, pelvic inflammatory diseases, and frequency of sexual intercourse were controlled for in the analyses.
\end{abstract}

Results-256 Periods of TTP or PUNP were reported by men and 174 by women. After exclusion of induced abortions, birth control failures, and periods without employment for female workers we were able to analyse 169 periods in men and 100 periods in women. Male workers who had been exposed to different concentrations of toluene and their partners did not show a reduction in fecundity. In women (39 periods occurred during exposure) fecundity was reduced (FR $0.47,95 \%$ confidence interval (95\% CI) 0.29 to 0.77$)$. Neither, restriction to only the first period nor exclusion of PUNPs changed the results (FR 0.48, 95\% CI 0.24 to 0.97).

Conclusion-After considering possible biases, low daily exposure to toluene in women seems to be associated with reduced fecundity. This result is in accordance with other findings for organic solvents and supports both the hypotheses that $(a)$ organic solvents could affect hormonal regulation, and that $(b)$ organic solvents increase early fetal losses which in turn contributes to longer times of unprotected intercourse.

(Occup Environ Med 1999;56:443-448)

Keywords: fecundity; organic solvents; time to pregnancy

Effects of exposure to organic solvents on human reproduction have been examined in several epidemiological studies focusing mainly on pregnancy outcomes. ${ }^{1-5}$ Increased rates of spontaneous abortions have been found in women. However, only a few studies have investigated toluene. ${ }^{467}$ Increased rates of spontaneous abortions or lowered birth weights have been found in the case of paternal exposure to toluene in the printing industry, or to other organic solvents used in refineries or in the automobile industry. ${ }^{8-11}$ Low and high exposure of male employees to toluene and benzene have also been found to be significantly correlated with morphological chromosomal aberrations. ${ }^{12}{ }^{13}$ However, in other studies, the rate of spontaneous abortion in partners of exposed men was not increased. ${ }^{14} 15$

An effect of organic solvents on serum hormone concentrations was first found in animals. ${ }^{16}{ }^{17}$ Studies on male employees in the printing industry found that both high ${ }^{18}$ and low exposure to toluene ${ }^{1920}$ were associated with an imbalance of sexual hormones in serum samples. A recent epidemiological study reported an increase in time to pregnancy (TTP) in the case of non-specific maternal exposure to different organic solvents. ${ }^{21}$

Time to pregnancy has been used as a sensitive instrument to identify the effect on fecundity for occupational exposure $e^{22-24}$ or lifestyle components..$^{25-27}$ We here present data on TTP relative to exposure to toluene from a study that was initiated by the Employer's Liability Insurance of the printing industry in Germany in the year 1993.

\section{Methods}

STUDY POPULATION

Toluene is used in the printing of coloured illustrations in media such as catalogues and magazines. Men and women working in the 14 largest German printing companies were informed about the study through the Employer's Liability Insurer and the printer's trade union. Eleven companies participated in the study. A representative cross section of 300 male workers was recruited by stratified random sampling according to the proportion of employees in the individual companies compared with the total population of 5024 male workers. Due to recent job cuts the total population of female workers (stacking and bookbinding) had fallen to 231 women. All of these on the payroll were approached, which also included women potentially on maternity leave.

\section{DATA COLLECTION}

Face to face interviews were conducted by trained female interviewers at the homes of the 
Table 1 Different levels of exposure to toluene in industrial settings of the German printing industry according to occupation and area of work based on measurements in different years and areas

Estimated mean exposure through air $/ \mathrm{h}\left(\mathrm{ppm} / \mathrm{m}^{3}\right)$

\begin{tabular}{llll} 
Area of work & Low $(<10)$ & Medium (10-30) & High (<200 before 1984,<100 1984-94,<50 after 1994*) \\
\hline Printing area & & $\begin{array}{l}\text { Exchange cylinders, } \\
\text { change ink rolls }\end{array}$ & $\begin{array}{l}\text { Printers, printing assistants, ink mixers and controllers, } \\
\text { machine operators and cleaners, handle product straight } \\
\text { from the press }\end{array}$ \\
$\begin{array}{ll}\text { Preparation area for quoins } \\
\begin{array}{l}\text { Area for stacking catalogues, } \\
\text { bookbinding }\end{array}\end{array}$ & $\begin{array}{l}\text { Engraving, galvanising, plating of zinc or } \\
\text { copper, grinding of cylinders } \\
\text { All occupations in this area }\end{array}$ & $\begin{array}{l}\text { Correction of } \\
\text { cylinders }\end{array}$ & $\begin{array}{l}\text { Plumbers, machine fitters or electricians working in } \\
\text { printing areas }\end{array}$ \\
& $\begin{array}{l}\text { Administrator, office clerks, canteen, } \\
\text { plumber or electrician outside the } \\
\text { printing site }\end{array}$ &
\end{tabular}

^ Different exposure levels of printing machines due to technical progress.

employees, as, with few exceptions, participating companies did not permit interviewing during working hours. Mean duration of the interviews was 30 minutes for men and about 45 to 60 minutes for women. All participants gave written informed consent. Quality control measures for processing the data included double data input, controls for plausibility, and when possible, correction of implausible data.

QUESTIONNAIRE

This study used a modified version of the European study on infertility and subfecundity questionnaire. ${ }^{28}$ The history of every period which could have ended in a pregnancy was recorded regardless of the pregnancy outcome. This included TTPs as well as periods of unprotected intercourse not leading to pregnancy (PUNPs). The two different periods (TTP or PUNP) are called time of unprotected intercourse (TUI), independent of their outcome. Data on induced abortion were not gathered to avoid difficult emotional situations. In five men and one woman employee, missing data on the month and week of the beginning of the TTP (the year was not missing) were replaced by mid-year (six months) estimates.

Data were solicited on pelvic inflammatory diseases, on reproductive organ surgery, and on chronic metabolic disorders-such as diabetes or hyperthyroidism. Lifestyle factors - such as consumption of alcohol, tobacco, or use of medications were ascertained for both men and women.

Data on working history included job descriptions, their duration (month and year of beginning and ending) and the tasks. Also, men working on printing machines were asked to describe the type of equipment and their brand name.

ASSESSMENT OF EXPOSURE

In the German printing industry (gravure printing, working with an intaglio) toluene has been used exclusively as a solvent since 1960 . Exposure at work was categorised into three groups (table 1) and one unexposed group according to exposure measurements in previous years conducted by industrial hygienists of the Employer's Liability Insurer (table 1). Allocation of different individual periods to exposure categories was based on work history. Information on printing machines and brand name used in the printing industry, their emission of toluene, and the use of closed systems, was obtainable from 1960 onward and was taken into consideration (table 1).

Men often worked directly on the printing machines as ink controllers or operators (high exposure), in the preparation of cylinders and quoins as galvanisers (medium exposure), or in other parts of the process, where printed material was handled, catalogues and magazines were stacked, or in bookbinding (low exposure). Exposure from stacking and bookbinding results from the release of volatile components of printed paper, which is sealed before it leaves the printing area and then opened again for stacking and binding.

Exposure in special jobs-such as plumbing or electrical work in the printing industry-is not identifiable through measurements of different workplaces and was assessed individually. These employees are potentially exposed to extremely high doses of toluene when working close to printing machines-for example, maintaining the system of evacuating and recycling toluene-or low doses when only operating in a control centre.

The women considered in our study worked exclusively in the stacking and bookbinding process. Their overall exposure therefore was classified as low. All assignments to the exposure classes were reviewed by the Employer's Liability Insurance.

The different exposure categories were then assigned to the TUIs in the respective time window. For men who experienced different exposure levels, we used information on current and previous exposure to check misclassification due to a recent change in the current exposure category.

\section{STATISTICAL ANALYSIS}

Descriptive comparisons are provided for men and women working in the printing industry with and without exposure. The units for the multivariate analyses, however, are periods, not people.

To compare the fecundability in exposed and unexposed periods we estimated the fecundability ratio (FR) based on TTPs and PUNPs. The PUNPs are censored observations. These are to reduce recall bias, available only for 5 years before the interview. As sampling was conducted from those who were on the payroll, PUPs are more likely to occur in exposed people. To exclude this bias, we also analysed the distribution of TTPs without PUNPs. 


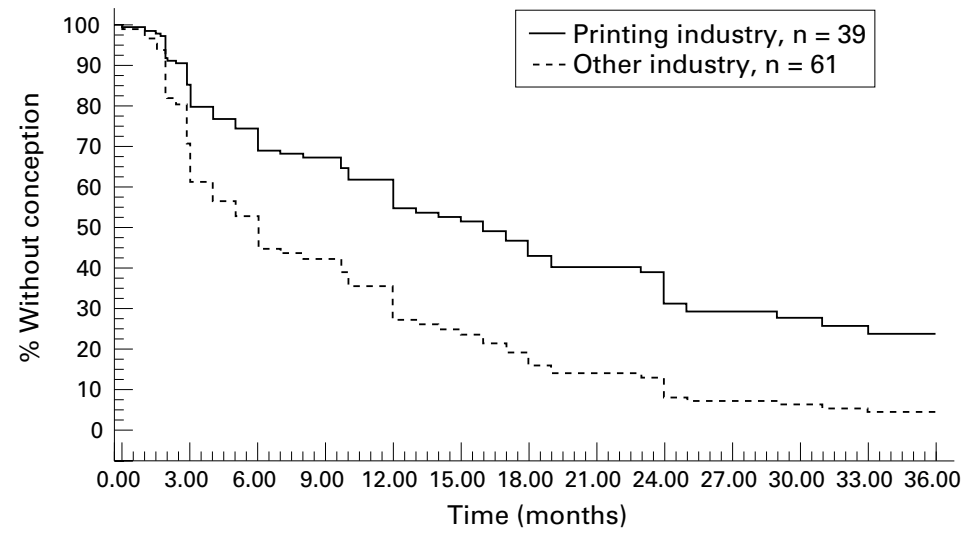

Time of unprotected intercourse in female employees exposed and unexposed to toluene $(n=100)$.

Pregnancies occurring in women currently using birth control measures were excluded from the analysis because, for these cases, it is not possible to obtain data on TTP.

To reduce the infertile worker effect ${ }^{29-31}$ we excluded TUIs which occurred while women stayed at home - for example, maternity leave and the time after-even if the woman was at risk of pregnancy due to unprotected intercourse.

We applied survival analyses to estimate the relation between exposure to toluene and fecundity with the Cox's proportional hazards model and the PHREG procedure. ${ }^{32-34}$ To account for the occurrence of ties, exact maximum likelihood estimates were computed. With the Cox's model we estimated the probability of conceiving among women exposed compared with those unexposed. Survival probabilities are plotted over observation period (figure). The hazard ratio was used as an estimate of the fecundability ratio and 95\% confidence intervals (95\% CIs) were calculated.

Regression models included the following potential confounders: age at starting time of unprotected intercourse, smoking, parity, ethnicity, pelvic inflammatory diseases, planning of the pregnancy, and frequency of intercourse. Confounders, however, were excluded when their elimination did not change the exposure estimate by at least $10 \%{ }^{35}$

\section{Results}

Eleven of the 14 largest companies in the German printing industry participated in the study. The overall participation after two posted letters and additional campaigning by the Employer's Liability Insurers and the trade unions was $50 \%$ for male workers $(n=150)$ and $39 \%$ for female employees $(n=90)$.

The ages of male workers did not differ significantly from the ages of all employees in the participating companies. Fifty seven per cent of the interviewed men were older than 40 (data not shown). Men working as printers directly handling printing machines or inks were slightly overrepresented, whereas workers in other fields such as preparing cylinders for the printing process or working with the finished product were slightly underrepresented.

The sample proportion of women differed significantly from total female employees in the printing industry for age (data not shown). More younger women participated in the investigation (30\% were born after $1960 v 7 \%$ of those non-participating). This, however, resulted in more than half of the exposed periods (TUI) dating from 1985 and later. Female subjects and the overall population of female workers in the printing industry did not deviate significantly for workplaces and jobs.

Twenty eight per cent of male workers were not German. Most male employees (91.3\%) were married or lived with a partner. More than $90 \%$ of all interviewed men had children, $15 \%$ had three or more. At the time of the interview, half of the female partners of male employees were at least 40 years of age.

Thirty six per cent of the women were not German. Most (84.4\%) were married or lived with a partner; $17.8 \%$ had had a divorce in the past; $91 \%$ had at least one child. The proportion of people without children was the same in female employees and in partners of male employees. Previous employment included a wide range of other exposures. However, none of the reported earlier jobs were notable for occupational risks related to subfecundity.

Table 2 Pregnancies (induced abortions excluded) and TUIs of female employees and of the partners of male employees

\begin{tabular}{|c|c|c|c|c|c|c|}
\hline & \multicolumn{6}{|c|}{ Consecutive number of TUI (pregnancy or PUNP) (n (\%)) } \\
\hline & 1 & 2 & 3 & 4 & 5 & 6 \\
\hline \multicolumn{7}{|l|}{$\begin{array}{l}\text { Male employees and their partners (227 } \\
\text { pregnancies or PUNPs). }\end{array}$} \\
\hline $\mathrm{n}$ & 117 & 71 & 28 & 8 & 2 & 1 \\
\hline Pregnancies despite contraception $(n=39)$ & $18(15.4)$ & $13(18.3)$ & $7(25.0)$ & $1(12.5)$ & 0 & 0 \\
\hline $\begin{array}{l}\text { Pregnancies resulting from unprotected } \\
\text { intercourse or PUNPs }(n=188)\end{array}$ & $99(84.6)$ & $58(81.7)$ & $21(75.0)$ & $7(87.5)$ & 2 & 1 \\
\hline TUI $\leqslant 12$ months & 77.7 & 81.0 & 85.0 & $\mathrm{n}=6$ & $\mathrm{n}=2$ & $\mathrm{n}=1$ \\
\hline TUI $>12$ months & 23.3 & 19.0 & 15.0 & $\mathrm{n}=1$ & 0 & 0 \\
\hline Missing data on TUI & 5 & 0 & 1 & 0 & 0 & 0 \\
\hline \multicolumn{7}{|l|}{$\begin{array}{l}\text { Female employees ( } 152 \text { pregnancies or } \\
\text { PUNPs): }\end{array}$} \\
\hline $\mathrm{n}$ & 72 & 47 & 20 & 8 & 3 & 2 \\
\hline $\begin{array}{l}\text { Pregnancies despite contraception }(n=29) \\
\text { Pregnancies resulting from unprotected }\end{array}$ & $10(13.9)$ & $9(19.1)$ & $7(35.0)$ & $2(25.0)$ & 0 & 1 \\
\hline intercourse or PUNPs $(n=123)$ & $62(86.1)$ & $38(80.9)$ & $13(65.0)$ & $6(75.0)$ & 3 & 1 \\
\hline TUI $\leqslant 12$ months & 68.3 & 67.6 & 61.5 & 33.3 & $n=3$ & $n=1$ \\
\hline TUI $>12$ months & 31.7 & 32.4 & 38.5 & 66.6 & 0 & 0 \\
\hline Missing data on TUI & 2 & 1 & 0 & 0 & 0 & 0 \\
\hline
\end{tabular}


Table 3 Distribution (\%) of duration of TUIs in interviewed female employees comparing occupations exposed and not exposed to toluene

\begin{tabular}{|c|c|c|c|c|c|c|}
\hline & \multicolumn{6}{|c|}{ Time to pregnancy in months } \\
\hline & $0-3$ & $4-12$ & $13-24$ & $24-36$ & $>36$ & Total \\
\hline \multicolumn{7}{|c|}{ TTPs and PUNPs while working in the printing industry: } \\
\hline $\mathrm{n}=39$ periods & 28.2 & 20.5 & 20.5 & 18.0 & 12.8 & 100 \\
\hline Only TTPs (n=28) & 28.6 & 17.9 & 25.1 & 17.9 & 10.7 & 100 \\
\hline \multicolumn{7}{|c|}{ TTPs working outside the printing industry: } \\
\hline $\mathrm{n}=61$ periods & 26.2 & 41.0 & 21.3 & 6.6 & 4.9 & 100 \\
\hline
\end{tabular}

Table 4 Distribution (\%) of confounding variables at the beginning of TUIs ascertained from female employees exposed and not exposed to toluene (unit of observation=TUI)

\begin{tabular}{lll}
\hline Confounder & $\begin{array}{l}\text { TUIs with employment outside the } \\
\text { printing industry }(n=61 \text { periods) }\end{array}$ & $\begin{array}{l}\text { TUIs with employment in the } \\
\text { printing industry }(n=39 \text { periods })\end{array}$ \\
\hline Age (y): & 41.0 & \\
$\quad \leqslant 20$ & 42.6 & 12.8 \\
$21-25$ & 14.8 & 23.1 \\
$26-30$ & 1.6 & 35.9 \\
$\geqslant 30$ & 29.5 & 28.2 \\
Smoking (yes) & 11.5 & 59.0 \\
PID & 44.3 & 41.0 \\
Planned pregnancy & 16.4 & 56.4 \\
Not sure & & 12.8 \\
Frequency of intercourse: & 16.7 & \\
Daily & 64.8 & 16.2 \\
Minimum once a week & 13.0 & 67.6 \\
$2-4$ times/month & 5.6 & 10.8 \\
About once a month & & 5.4 \\
Parity: & 50.8 & 48.7 \\
0 & 26.2 & 30.8 \\
1 & 13.1 & 12.8 \\
2 & 6.6 & 2.6 \\
3 & 3.3 & 2.6 \\
4 & 0 & 2.6 \\
5 & 42.6 & 53.9 \\
Nationality not German & & \\
\hline
\end{tabular}

TUI=time of unprotected intercourse.

Table 5 Fecundability ratio (FR) in women for periods of working in the printing industry compared with working in other industries

\begin{tabular}{|c|c|c|}
\hline & \multicolumn{2}{|c|}{$\begin{array}{l}\text { Analysed periods }(n=100) \\
\text { including } 11 \text { censored periods }\end{array}$} \\
\hline & $F R$ & $95 \% C I$ \\
\hline Working outside the printing industry & 1 & \\
\hline Working in the printing industry & 0.47 & 0.29 to 0.77 \\
\hline \multicolumn{3}{|l|}{ Smoking: } \\
\hline No & 1 & \\
\hline Yes & 0.76 & 0.47 to 1.22 \\
\hline Parity ( $0 v$ higher) & 0.88 & 0.57 to 1.36 \\
\hline \multicolumn{3}{|c|}{ Working in the printing industry and nationality: } \\
\hline Not German & 0.67 & 0.34 to 1.33 \\
\hline German & 0.31 & 0.13 to 0.72 \\
\hline
\end{tabular}

MALE EMPLOYEES

In total 256 pregnancies occurred in partnerships with the 150 male workers. Twenty four of which ended in an induced abortion and were therefore excluded from further questioning. Five pregnancies were excluded due to missing data. Of the remaining 227 pregnancies $39(17.2 \%)$ occurred in spite of contraception and were also excluded (table 2). Men and their partners contributed seven PUNPs. Missing data on potential confounders further reduced the numbers to 162 TTPs and seven PUNPs.

After adjustment for age and smoking of the partner no association between the duration of TUIs (TTP or PUNP) and the exposure of men to toluene could be identified (FR 1.05, 95\% CI 0.93 to $1.19, \mathrm{p}=0.43$ ). The use of four exposure categories did not have any effect on the result (no exposure (reference) $\mathrm{n}=65$ periods; low exposure category (table 1) FR 0.78 (95\% CI
0.47 to 1.29$), \mathrm{n}=27$ periods; medium exposure FR 0.81 (95\% CI 0.45 to 1.46$), n=17$ periods; high exposure FR 1.11 (95\% CI 0.75 to 1.62 ), $\mathrm{n}=60$ periods). Being exposed only at the time when the couples started to try to become pregnant also did not change this result (FR 1.08, $95 \%$ CI 0.96 to $1.22, p=0.20$ ), nor did a stratification for four periods with different technologies. However, only a small group of workers $(n=9)$ had experienced the potentially most hazardous conditions before 1960 .

FEMALE EMPLOYEES

Of the 90 interviewed women 74 had ever been pregnant. Of 175 reported TUIs (TTP or PUNP) 19 had to be excluded due to induced abortion, four due to missing data, and 29 due to contraceptive failures (table 2). Of the remaining 123 TUIs 23 occurred during periods without employment and are thus excluded from the analysis. Sixty women experienced at least one TUI during a period of employment and 23 women had at least two. Thirty one women experienced unexposed periods only, 25 exposed periods only, and four had both.

The information from the data of 89 TTPs and 11 PUNPs obtained from 60 women was entered in the Cox's model. The distribution of TUIs with or without exposure (employed in the printing industry or elsewhere) is shown in table 3. Variables acting as confounders for TUIs were not distributed evenly in the two groups (table 4): smoking and older age were found more often at the beginning of a TUI when the person was working in the printing industry compared with other sites.

The final model (table 5, figure) included the confounders smoking and parity at the beginning of the TTP. A strong association (FR $0.47,95 \%$ CI 0.29 to 0.77 ) between employment in the printing industry and the duration of the TUI was found when comparing 39 periods of 26 women under exposure with 61 periods of 34 women employed elsewhere (four women experienced both exposed and unexposed periods).

Analysis of TTPs only $(n=89)$ through exclusion of the 11 censored periods (PUNPs) resulted in a slightly less but still significantly reduced fecundability ratio $(\mathrm{FR}=0.52,95 \%$ CI: $0.28,0.99)$. Stratifying according to nationality showed a stronger and significant effect in German women (53 periods in 35 women, FR $0.31,95 \%$ CI 0.13 to 0.72 ) compared with 47 periods in 25 non-German women (FR $0.67,95 \%$ CI 0.34 to 1.33 ).

When only the first TUI of each woman was entered in the model ( 60 periods of which 53 were TTPs and seven periods were PUNPs) the fecundability ratio was still significantly reduced (FR $0.48,95 \%$ CI 0.24 to 0.97 ).

\section{Discussion}

We did not find an association between occupational exposure to toluene and subfecundity in men and their partners.

For periods of unprotected intercourse in female employees who worked in exposed areas a significant reduction of their fecundability of about $50 \%$ was found compared with periods 
working in other industries. The association is stronger in German women than in women of other nationalities.

The low participation rate is likely to introduce a selection towards less fertile people with a higher interest in participation. Male employees, nevertheless, represented the target population well for age and profession. However, the sample of women was significantly younger. Participation of younger women in a TTP study has been found elsewhere. ${ }^{21}$ Being of reproductive age could increase concern about reproductive hazards and could stimulate participation of younger women. The low proportion of conceptions occurring within a year (table 3) shows that more women with a low fecundity participated. However, the women were recruited from one population only-namely, workers with the task of bookbinding and stacking catalogues. The low proportion of participation might have introduced a selection of women who are more interested in infertility, due to previous experiences. However, the selection was the same for exposed and unexposed women, as 31 women experienced only unexposed periods (waiting times to pregnancies that occurred before their current employment), 25 experienced exposed periods, and four experienced both. As we only recruited from one group and the participants provided both exposed and unexposed periods, a selection of less fertile participants is likely to bias the results towards the null value, as reduced fertility in this sample would increase its background risk in non-exposed periods. Additionally, younger participants are likely to provide periods with lower exposure than older participants as machines have undergone technical improvement in recent years.

The assessment of exposure to toluene in the printing industry was based on job descriptions, on categorisation provided by the Employer's Liability Insurance, and on measurements made by industrial hygienists. Thus, a possible misclassification due to a recall bias on exposure seems to be of minor influence. As toluene has been exclusively used in the German printing industry since 1960, we can also be certain about the single effect of toluene.

Assessment of retrospective data is generally hampered by possible recall bias. In TTP studies one way to control for this is the restriction of data on the last pregnancy. ${ }^{30}$ Other authors claim information on pregnancy data to be reliably remembered. ${ }^{21}{ }^{36}$ Joffe et al found only minor differences between TTPs ascertained several years ago (median 14 years) in comparison with information gathered later. ${ }^{36}$ In our sample about $35 \%$ of periods in exposed and unexposed workers took place more than 14 years ago (maximum 22 and 25 years, respectively). We assume that a recall bias on most of the time specific details given by participants contributing both exposed as well as unexposed data is likely to be evenly distributed. However, we cannot exclude a better recall of TUIs in women who experienced reproductive problems. ${ }^{37}$ As a recall bias in duration of employment is unlikely, the recall of TUIs occurred for exposed and unexposed periods and thus was probably of minor importance.

An information bias could also result from the inclusion of PUNPs as these periods are restricted to the past 5 years and are thus more likely to be contributed by exposed women. However, excluding the 11 PUNPs in the analysis did not change the results.

We tried to minimise behaviour modification and medical intervention biases ${ }^{30}$ by taking medical data and lifestyle data at the starting of the TUIs into account. A planning bias arising from the exclusion of pregnancies occurring despite contraception can result in differential misclassification, either towards the null value or away from the null value. There is no reliable method of controlling for this bias. ${ }^{30}$

Confounders known to have an influence on TTP — such as smoking or age-were found to be more often associated with exposed periods but controlling for them did not have an effect on the results. Pelvic inflammatory diseases were more often found in exposed periods which is explained by the fact that older women are likely to have higher occurrence of both pelvic inflammatory disease and exposed periods. In our definition of pelvic inflammatory disease we included a history of appendicitis, which was the single cause of a potential pelvic inflammatory disease in nine of 23 periods or six of 18 women. There was no association between starting work in the printing industry and onset of a pelvic inflammatory disease.

When comparing the association of working in the printing industry and subfecundity of German and non-German women the differences are remarkable. German women had higher values of smoking and nulliparity. However, when controlling for these confounders, the difference in the effect remained. A possible reason for this could be an overall higher exposure to noxious substances of non-German women, as this group often carries out the dirtier work in Germany. Exposure to toluene could pose a weaker relative risk to women who experience higher exposures in other jobs outside the printing industry. This assumption is supported by a comparison of the median time to the first pregnancy, which was generally longer in non-German women (German women 5 months, $\mathrm{n}=35$; non-German women 7 months, $\mathrm{n}=25$ ).

Our findings on male fecundity show that an adverse effect is unlikely but cannot be completely excluded. A recently published study also did not identify an increased risk of subfecundity due to organic solvents in men. ${ }^{38}$ Thus, it is possible that the increased rate of spontaneous abortions described in other studies of male exposure ${ }^{9-11}$ is more likely to reflect chromosomal aberrations found in some studies relative to exposure to toluene ${ }^{12} 13$ rather than a hormonal imbalance leading to subfecundity.

Sallmen et $a l^{11}$ also found a reduced fecundability in women of 0.41 (95\% CI 0.27 to 0.62$)$ for high exposure and of 0.69 (95\% CI 0.48 to 0.99) for low exposure to organic solvents. Exposure in the low group was defined as any 
exposure 1-4 times a week. In their high exposure group any daily exposure was considered to be high and is comparable with the daily low exposure to toluene of women in the German printing industry. These results are consistent with ours, despite a lack of significance for a single effect of toluene in the study of Sallmen et al. $^{21}$

Other forms of exposure known to have an effect on fertility, such as noise at the workplace, shiftwork, or stress were not examined in our study and cannot therefore be excluded as having produced part of the findings or the overall result. Shiftwork is thought to reduce fertility of couples for many reasons, one of them being a reduced probability of becoming pregnant due to less frequent sexual intercourse. ${ }^{39}{ }^{40}$ In our study the frequency did not differ in the exposed and unexposed periods. Adverse effects of noise together with solvent exposure on fecundability were found to be stronger in women than in men. ${ }^{41}$ We cannot exclude such effects on the result of our study.

Biological plausibility can be provided when analysing effects of toluene on hormonal regulation in women and on early fetal losses. Possible changes in hormonal regulation ${ }^{42}{ }^{43}$ might clarify the biological basis for reduced fecundity, including changes either before conception or after implantation. Early fetal losses without effects on maternal hormones would indicate that only the fetus is affected. Thus we emphasise that having congruent results on subfecundity in two studies of women makes research on hormonal state and on early fetal losses in a female population exposed to organic solvents, especially to toluene, an urgent necessity.

We thank the Employer's Liability Insurer of the printing industry for supporting the study and for faciliating access to the printing companies. We very much appreciated the opportunity to approach workers, which was provided by the different plants and supported by the trade union. We are indebted to all the workers who were willing to give us the time for the interviews. Last but not least we thank Ingrid Kandt and the interviewers for the logistic and technical work.

1 McDonald AD, McDonald JC, Armstrong B, et al. Fetal death and work in pregnancy. Br F Ind Med 1988;45:14857.

2 Lipscomb JA, Fenster L, Wrensch M, et al. Pregnancy outcomes in women potentially exposed to occupational solvents and women working in the electronics industry. $f$ Occup Med 1991;33:597-604

3 Windham GC, Shusterman D, Swan SH, et al. Exposure to organic solvents and adverse pregnancy outcome. Am f Ind Med 1991;20:241-59.

4 Lindbohm ML, Taskienen H, Sallmen M, et al. Spontaneous abortions among women exposed to organic solvents. Am f Ind Med 1990;4:449-63.

5 Lindbohm ML. Effects of parental exposure to solvents on pregnancy outcome. F Occup Environ Med 1995;8:908-14. pregnancy outcome. $\mathcal{F}$ Occup Environ Med 1995;8:908-14.
Ng TP, Foo SC, Yoong T. Risk of spontaneous abortion in $\mathrm{Ng}$ TP, Foo SC, Yoong T. Risk of spontaneous abortion in
workers exposed to toluene. Br f Ind Med 1992;49:804-8. workers exposed to toluene. Br f Ind Med 1992;49:804-8.
7 Taskienen H, Kyyronen P, Hemminki K, et al. Laboratory work and pregnancy outcome. F Occup Med 1994;3:311-9.

8 Lindbohm ML. Effects of parental exposure to solvents and lead on spontaneous abortion. Scand $\mathcal{f}$ Work Environ Health 1992;18:37-9.

9 Taskienen H, Anttila A, Lindbohm ML, et al. Spontaneous abortion and congenital malformations among the wives of men occupationally exposed to organic solvents. Scand $\mathcal{F}$ Work Environ Health 1989;15:345-52.

10 Lindbohm ML, Hemminki K, Bonhomme MG, et al. Effects of paternal occupational exposure on spontaneous abortions. Am f Public Health 1991;81:1029-33.

11 Kristensen P, Irgens LM, Daltveit AK, et al. Perinatal outcome among children of men exposed to lead and
organic solvents in the printing industry. Am $\mathcal{F}$ Epidemiol 1993;137:134-44.
12 Rendon, A, Rojas A, Fernandez SI, et al. Increase in chromosome aberrations and in abnormal sperm morphology in rubber factory workers. Mutat Res 1994;4:151-7.

13 Karacic V, Skender L, Bosner CB, et al. Possible genotoxicity in low level benzene exposure. Am $f$ Ind Med 1995;3:379-88.

14 Stücker I, Mandereau L, Aubert-Berleur MP. Ocupational paternal exposure to benzene and risk of spontaneous abortion. Occup Environ Med 1994;51:475-8.

15 Eskenazi B, Fenster L, Hudes M, et al. A study of the effect of perchloroethylene exposure on the reproductive outcomes of wives of dry-cleaning workers. Am f Ind Med 1991;20:593-600.

16 Andersson K, Fuxe K, Toftgard R, et al. Toluene-induced activation of certain hypothalamic and median eminence catecholamine nerve terminal systems of the male rat and its effects on anterior pituitary hormone secretion. Toxicol Lett 1980;5:393-8.

17 Andersson K, Fuxe K, Nilsen OD, et al. Production of discrete changes in dopamine and noradrenaline levels and turnover in various parts of the rat brain following exposure to xylene, ortho- meta- and para-xylene and ethylbenzene. Toxicol Appl Pharmacol 1981;60:535-48.

18 Moerck HI, Winkel P, Gyntelberg F. Health effects of toluene exposure. Dan Med Bull 1988;35:196-200.

19 Svensson BG, Nise G, Erfurth EM, et al. Neuroendocrine effects in printing workers exposed to toluene. $\mathrm{Br} \mathcal{F}$ Ind $\mathrm{Med}$ 1992;49:402-8.

20 Svensson BG, Nise G, Erfurth EM, et al. Hormone status in occupational toluene exposure. Am f Ind Med 1992;22:99_ 107.

21 Sallmen M, Lindbohm ML, Kyyrönen P, et al. Reduced fertility among women exposed to organic solvents. Am f Ind Med 1995;27:699-713.

22 Baird DD, Wilcox AJ. Effects of occupational exposures on the fertility of couples. Occupational Medicine 1986;1:361-

23 Schaumburg I, Olsen J. Time to pregnancy among Danish pharmacy assistants. Scand $\mathcal{F}$ Work Environ Health 1989;15: 222-6.

24 Rowland AS, Baird DD, Weinberg CR, et al. The effect of occupational exposure to mercury vapour on the fertility of female dental assistants. Occup Environ Med 1994;51:28-4.

25 Baird DD, Wilcox AJ. Cigarette smoking associated with delayed conception. $\mathcal{f} A M A$ 1985;253:2979-83.

26 Olsen J. Cigarette smoking, tea and coffee drinking and subfecundity. Am F Epidemiol 1991;7:734-9.

27 Hatch EE, Bracken MB. Association of delayed conception with caffeine consumption. Am f Epidemiol 1993;138: 1082-92.

28 Karmaus W, Juul S. Infertility and subfecundity in population-based samples from Denmark, Germany, Italy, Poland, and Spain. 1999 European Fournal of Public Health (in press)

29 Joffe M. Biases in research on reproduction and women's work. Int F Epidemiol 1985;14:118-23.

30 Weinberg C, Baird DD, Wilcox A. Sources of bias in studies of time to pregnancy. Stat Med 1994;13:671-81.

31 Lemasters GK, Pinney SM. Employment status as a confounder when assessing occupational exposures and spontaneous abortion. F Clin Epidemiol 1989; 42:975-81.

32 Cox DR, Oakes A. Analysis of survival data. London: Chapman and Hall, 1984.

33 SAS Institute. SAS/STAT user's guide. Vols 1 and 2. Cary, NC: SAS Institute, 1990

34 Baird DD, Wilcox AJ, Weinberg CR. Use of time to pregnancy to study environmental exposures. $A m \mathcal{F}$ Epidemiol 1986;3:470-80.

35 Greenberg RS, Kleinbaum DG. Mathematical modeling. Strategies for the analysis of epidemiologic research. Ann Rev Public Health 1985;6:223-45.

36 Joffe M, Villard L, Li Z, Plowman R, et al. Long-term recall of time-to-pregnancy. Fertil Steril 1993;60:99-104.

37 Joffe $M$. Feasibility of studying subfertility using retrospective self reports. I Epidemiol Community Health 1989;43: 268-74

38 Sallmen M, Lindbohm ML, Anttila A, et al. Time to pregnancy among the wives of men exposed to organic solvents. Occup Environm Med 1998;55:24-30.

39 Bisanti L, Olsen J, Basso O, et al. Shift work and subfecundity: a European multicenter study. $\mathcal{F}$ Occup Med 1996;38:352-8.

40 Runge J, Karmaus W. Einfluß von Nacht- und Schichtarbeit auf Fertilität und Schwangerschaft. In: Brähler E, Schumacher J eds. Psychologie und Soziologie in der Medizin. Gießen, Germany: Psychosozial-Verlag, 1996:156-7.

41 Rachootin P, Olsen J: The risk of infertility and delayed conception associated with exposures in the Danish workplace. f Occup Med 1983;25:394-402.

42 Stepanov MG, Altukhov VV, Proimina FI, et al. Physiologic mechanism of the reaction of the reproductive system in female rats to chronic exposure to low doses of toluene. Fiziol Zh SSSR Im I M Sechenova 1990:8:1096-102.

43 Wilcox AJ, Weinberg CR, Baird DD, et al. Endocrine detection of conception and early foetal loss. In: Gray R, Leridon $\mathrm{H}$, Spira A, eds. Biomedical and demographic determinants of reproduction. Oxford: Clarendon Press, 316-28. 